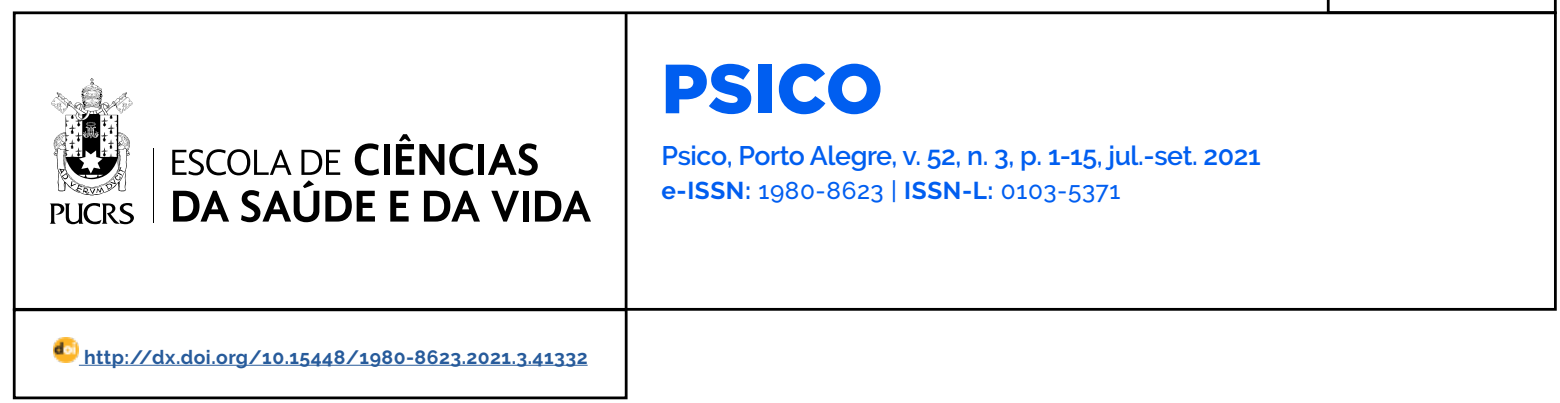

SEÇÃO: ARTIGO

\title{
A longitudinal model for psychological distress in the COVID-19 crisis among brazilian graduate students
}

\author{
Um modelo longitudinal de sofrimento psicológico na crise da COVID-19 entre pós- \\ graduandos brasileiros \\ Un modelo longitudinal de sufrimiento psicológico en la crisis del COVID-19 entre \\ posgraduados brasileños
}

\author{
Marcela Mansur-Alves ${ }^{1}$ \\ orcid.org/0000-0002-3961-3475 \\ marmansura@gmail.com
}

Cristiano Mauro Assis Gomes ${ }^{1}$ orcid.org/0000-0003-3939-5807 cristianomaurogomes@gmail.com

Camila Batista Peixoto ${ }^{1}$

orcid.org/0000-0002-6999-9460 camimilabp@gmail.com

Matheus Bortolosso Bocardi ${ }^{1}$ orcid.org/0000-0001-6432-1661 matheusbocardi@gmail.com

Marina Luiza Nunes Diniz ${ }^{1}$ orcid.org/0000-0002-1198-1858 marinaluizanunesd@gmail.com

Sabrina Kelly Pessoa de Freitas ${ }^{1}$ orcid.org/0000-0001-7001-9354 sabrinafreitas.psico@outlook.com

Elder Gomes Pereira ${ }^{1}$

orcid.org/0000-0002-6368-5698 elder.gomespsi@gmail.com

Juliana Alvares-Teodoro ${ }^{1}$ orcid.org/0000-0002-0210-0721 jualvares@gmail.com

Pricila Cristina Correa Ribeiro ${ }^{1}$ orcid.org/0000-0001-9431-2707 priccr@gmail.com

Maycoln Leôni Martins Teodoro ${ }^{1}$ orcid.org/0000-0002-3021-8567 mlmteodoro@hotmail.com

Recebido em: 19 jul. 2021. Aprovado em: 28 jul. 2021. Publicado em: 27 out. 2021.

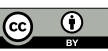

Artigo está licenciado sob forma de uma licença Creative Commons Atribuição 4.0 Internacional.
Abstract: As most evidence for mental health impacts of the COVID-19 crisis is cross-sectional, the present study aimed to analyze the longitudinal development of psychological suffering among 619 Brazilian adults by assessing mental health outcomes and individual factors in two periods: a year before and a month after the break of the pandemic. As major findings, pandemic psychological suffering was directly explained by previous-year suffering, conscientiousness, and pandemic perceived stress, and correlated with pandemic suicidal ideation. Pandemic perceived stress correlated with pandemic psychological distress, and was explained by previous-year suffering, neuroticism, and conscientiousness, as well as by pandemic life satisfaction and perceived pandemic impact. Finally, pandemic suicidal ideation variance was explained by prior ideation and pandemic life satisfaction. These findings are in line with current models of mental health and highlight the importance of integrating both more stable individual factors and more transient variables towards an explanation for mental health outcomes. Keywords: mental health, COVID-19 pandemic, longitudinal, personality

Resumo: Evidências dos impactos da crise da COVID-19 sobre a saúde-mental são em sua maioria transversais. Portanto, o presente estudo propôs-se a analisar o desenvolvimento longitudinal do sofrimento psicológico de 619 adultos brasileiros, avaliando fatores individuais e desfechos de saúde-mental em dois tempos: um ano antes e um mês após a deflagração da pandemia. O nível de sofrimento um mês após o início da pandemia foi explicado pelo sofrimento $e$ conscienciosidade prévios e por estresse percebido na pandemia, correlacionando-se com ideação suicida pandêmica. Estresse percebido na pandemia foi explicado por neuroticismo, conscienciosidade e sofrimento anteriores, bem como por satisfação com a vida e impacto percebido na pandemia. Por fim, ideação suicida pandêmica foi explicada por ideação prévia e satisfação com a vida na pandemia. Esses achados corroboram modelos atuais de saúde-mental e ressaltam a importância de se integrar tanto fatores individuais estáveis quanto variáveis transientes à explicação de desfechos de saúde-mental.

Palavras-chave: saúde mental, pandemia da COVID-19, longitudinal, personalidade

Resumen: Evidencia de los impactos de la crisis del COVID-19 en la salud-mental es mayoritariamente transversal. Así, el presente estudio tuvo como objetivo analizar el desarrollo longitudinal del sufrimiento psicológico en 619 adultos brasileños, evaluando factores individuales y de salud-mental en dos periodos: un año antes y un mes después del brote de la pandemia. Sufrimiento psicológico pandémico se explica por sufrimiento y conscienciosidade anteriores y por estrés pandémico percibido, correlacionando con ideación suicida pandémica. Estrés percibido en la pandemia se correlacionó con sufrimiento psicológico pandémico y se explicó por neuroticismo, conscienciosidade y sufrimientos previos, asi como por satisfacción con la vida y el impacto percibido pandémicos. Finalmente, ideación suicida pandémica se explica por ideación previa y satisfacción con la vida en la pandemia. Estos 
resultados corroboran modelos actuales de salud-mental y subrayan la importancia de integrar tanto factores individuales estables como variables transitorias en la explicación de resultados de salud-mental.

Palabras clave: salud mental, pandemia del COVID-19, longitudinal, personalidad

The World Health Organization (WHO) declared the COVID-19, the novel SARS-CoV-2 coronavirus disease, a pandemic in March 2020, after its fast spread around the globe as of 2019. In Brazil, a state of emergency was declared on February 3 . 2020 (Ministério da Saúde, 2020a), the first case was confirmed in the 26th, and the first death, on March 17, 2020 (Ministério da Saúde, 2020b), with subsequent adoption of several sanitary policies for the containment of the pandemic. Pandemics and public health emergencies are associated not only with economic, sociopolitical, and human tolls, but also with important detrimental effects over the population's mental health (Brooks et al., 2000; Zortea et al. 2020).

The number of studies that demonstrate these mental health effects in the COVID-19 context is growing fast (e.g., Ammerman et al., 2020; Casali et al., 2020; Wang et al. 2020a; Wetherall et al., 2020). A meta-analysis conducted by Salari et al. (2020) synthesize the high rates of symptoms of stress, anxiety and depression found among the general population across several countries following the pandemic, estimated at 29.6\% (95\% Cl: $24.3-35.4$ ), 31.9\% (95\% Cl: 27.5-36.7) and 33.7\% (95\% Cl:27.5-40.6), respectively. Findings also indicate positive associations between poor mental health and perceived stress (Ammerman et al., 2020; Pradhan et al., 2020), as well as negative associations between poor mental health and life satisfaction (Morales-Vives et al., 2020; Zhang et al., 2020). Socio-demographic variables that are frequently associated with COVID related mental health impairment include age, gender, financial stress, sexual orientation, psychiatric history, chronic diseases, among others (e.g., Di Crosta et al., 2020; Kneale \& Becares, 2020; OzamizEtxebarria et al, 2020; Suen et al., 2020; Wang et al. 2020a). Moreover, previous epidemics have shown increased frequency of suicidal behavior, with post- pandemic rates higher than the pre-pandemic ones even a year after (Zortea et al. 2020).

Personality traits are also being investigated as potential predictors or moderators of mental health outcomes and attitudes towards the pandemic. Neuroticism is associated with a greater individual tendency to experiencing negative emotions, vulnerability, emotional instability, and reactivity when facing distressing events, and regarded as an important independent predictor of several physical and mental health outcomes (McCrae \& Sutin, 2018). During the pandemic, amounting evidence shows that the levels of neuroticism, even after controlling for socio-demographic characteristics, have positively and significantly correlated with intensity of fear towards the virus, feelings of boredom, and negative fantasies (Caci et al., 2020); to perceived stress and perceived threat (Liu et al., 2021); as well as to health-related anxiety, COVID related anxiety, and anxious and depressive symptoms (Nikčević et al., 2020).

Another Big-Five personality trait related to coping with COVID is conscientiousness, which, generally, describes a tendency towards feelings, thoughts and behaviors of control, self-efficacy, commitment, responsibility, discipline, parsimoniousness, and order (Sutin \& McCrae, 2018). During the COVID-19 pandemic, conscientiousness has been associated with greater propensity and ease towards following and adhering to preventive measures, pandemic containment and social distancing (e.g., Carvalho et al., 2020). Furthermore, higher levels of conscientiousness are associated with greater self-efficacy for infection prevention, and with reduced perceived stress during the pandemic (Liu et al., 2021), as well as with greater subjective well-being (Modersitzki et al., 2020), lower levels of health anxiety and COVID related anxiety and, consequently, decreased symptoms of depression and generalized anxiety (Nikčević et al., 2020).

However, most of cumulative evidence regarding individual associated factors and potential mental health predictors in the context of the COVID-19 pandemic are restricted to 
cross-sectional data, which are not sufficient to establish causality. Among the few existing longitudinal studies, there is conflicting evidence regarding psychological impact (Prati \& Mancini, 2021). Some did not find statistically nor clinically relevant change amidst mental illness measures or found a reduction of these (e.g., China, Wang et al., 2020b; Argentina, Juric et al. 2020), whereas other studies have identified increased fear, preoccupation, and symptoms related to stress, anxiety, and depression throughout the pandemic (e.g., Espanha, Planchuelo-Gómez et al., 2020; Multicultural, Lippold et al., 2020). Most of these studies, nonetheless, have demonstrated significant differences in respect of several COVID related variables (e.g., showing symptoms, being part of a risk group, knowing someone who has been infected, and others) as well as in respect of age and gender, with younger participants and women showing worse effects (e.g, Juric et al., 2020; Lippold et al., 2020; PlanchueloGómez et al., 2020). Other socio-demographic factors (e.g., educational level, marital status, occupational status, and others) yielded diverse results, and sexual orientation data were not analyzed in the identified longitudinal studies, despite cross-sectional evidence of LGBTQ+ groups being significantly more affected (Suen et al., 2020). Finally, only Lippold et al. (2020) included personality individual differences and concluded that neuroticism was the best predictor of fear and preoccupation related to the pandemic, after controlling for political orientation, risk group status, gender, and educational level. Importantly, although the four cited studies had a large number of participants, their follow-up intervals were of approximately 2 to 5 weeks, starting from the beginning of the pandemic, and two of them analyzed changes between non-coinciding groups across time (Lippold et al., 2020; Wang et al., 2020b). Thus, only two of the studies have performed totally or partially paired analysis, i.e., for the exact same participants along a time period (Juric et al., 2020; Planchuelo-Gómez et al., 2020).

In this sense, the main objective of the present study was to analyze the longitudinal development of mental suffering among a sample of Brazilian adults by comparing two periods: pre-pandemic (2019) and pandemic (2020). For the construction of the longitudinal model through path analysis, the following variables were considered: a) as outcome variables: pandemic frequency of suicidal ideation and symptoms of anxiety, stress and depression (general psychological suffering); b) as predictor variables: personality characteristics (pre-pandemic neuroticism and conscientiousness levels), pre-pandemic symptoms of anxiety, stress and depression, pre-pandemic life satisfaction, as well as pandemic life satisfaction and frequency of suicidal ideation; and finally, c) as mediator variables: perceived stress during the pandemic and subjective perception of the pandemic impact over one's life. Furthermore, the metric, configural and scalar invariance of the scales were tested between the two time periods of the study (2019 and 2020), as well as the invariance of the longitudinal model in respect of participants gender and sexual orientation, since literature points out that individuals of different genders and sexual orientations experience psychological distress in significantly different levels (Auerbach et al., 2018; Kneale \& Becares, 2020; Suen et al., 2020).

\section{Method}

\section{Participants}

The participants of the current study were part of both a 2019 project, which investigated mental health among post-graduate students, and a subsample of a broader 2020 project concerning the effects of the pandemic over several different groups of the population. In total, 619 adult post-graduate Brazilian students, from different geographic regions, were assessed throughout March and July of 2019 and then reassessed in April 2020. The sample was predominantly comprised of women ( $n=450,72.2 \%$ in 2019 and 2020) and heterosexuals ( $n=499,80.6 \%$ in 2019; $n=$ $482,77.9 \%$ in 2020 ) in both data collection periods. Age ranged from 21 to 63 years $(M=30.01$ years; $D P$ $=6.36)$ in 2019, and from 22 to 64 years $(M=31.75$; $D P=6.35)$ in 2020. In 2020, participants reported they had been social distancing for approximately 4 weeks by the time data was collected. 


\section{Measures}

Socio-demographic characterization and pandemic perception questionnaire. The authors developed a structured questionnaire that included socio-demographic (age, gender, race/ethnicity and sexual orientation) and COVID-19 related questions. The only COVID-19 related item included in the present study evaluated the subjective perception of the impact of the pandemic over the participants' life, the Pandemic Impact variable. The item asked, "How much has your life and yourself been affected by the COVID-19 pandemic" and provided 4 possible answers, ranging from "Neutral, I do not think I have been affected as much as other people yet" to "Very much affected".

Depression, Anxiety, and Stress Scale - DASS-21 (Lovibond \& Lovibond, 1996). The DASS-21 scale measures several depression, anxiety, and stress symptoms through a 4-point Likert scale. Scores vary from 0 to 63 , in which higher scores mean greater impairment to mental health. The Brazilian version (Vignola \& Tucci, 2014) exhibits satisfactory internal consistency values (Cronbach's alfa of 0.86 for anxiety, 0.90 for stress, and 0.92 for depression). In the present study, the total score in DASS-21 was used as an indicator of psychological distress for both 2019 and 2020 periods, and each was coded as DASS2019 and DASS2020.

\section{Big Five Inventory - BFI (John, Donahue \&} Kentle, 1991). The Brazilian version of the Big Five Inventory is the Inventário dos Cinco Grandes Fatores de Personalidade, IGFP-5 (Andrade, 2008). It was adapted to Brazilian Portuguese and is made up of 44 items, distributed among the five big factors of personality (i.e., Openness to Experience, Conscientiousness, Extroversion, Agreeableness, and Neuroticism). Reliability coefficients vary from 0.78 to 0.76 (Guttman's lambda-2). Each item is answered through a Likert scale from 1 to 5 ( 1 = "Never" and 5 = "Frequently"). In the present study, only the 17 items that comprise the neuroticism ( 8 items) and conscientiousness (9 items) factors were considered. Participants were asked to answer to this scale only in 2019 . and subscales scores were coded accordingly as Neurot2019 and Consc2019.

Satisfaction with Life Scale - SWLS (Diener, Emmons, Larsen, \& Griffin, 1985). SWLS measures life satisfaction through 5 items with a 7-point answer scale, that goes from 1 ("I totally disagree") to 7 ("I totally agree"). The Brazilian version presents a unifactorial structure and an adequate reliability index (Cronbach 's Alpha = 0.81, Gouveia et al., 2009). SWLS scores vary from 5 to 35 . and a higher score means greater perception of satisfaction with life. This scale was part of the administered instruments in 2019 (score coded as SWLS2019) as well as in 2020 (score coded as SWLS2020).

Frequency of Suicidal Ideation Inventory - FSII (Chang \& Chang, 2016). FSII comprises 5 items that evaluate the frequency of suicidal ideation along the last 12 months through a 5-point Likert scale that varies from 1 ("never") to 5 ("almost every day"). The Brazilian version, FSII-Br, shows good psychometric properties and a Cronbach's Alpha of 0.88 for its single factor (Teodoro et al., 2020). FSII total scores vary from 5 to 25 points, and higher scores mean higher frequency of suicidal ideation in the last 12 months. This scale was completed by participants at both periods, 2019 and 2020, and total scores correspond to FSII2O19 and FSII2O20 variables.

\section{Perceived Stress Scale - PSS (Cohen, Kamarck,} \& Mermelstein, 1983). We used the 14-item version, in which answers are organized in an ordinal scale of 5 points that vary from "never" to "very frequently". Each item can receive values from o to 4 and, accordingly, minimum total score is 0 and maximum total score is 56 . The greater the total score, the smaller is the degree of confidence that one's life has been unpredictable, uncontrollable and overwhelmed in the month before the assessment. The Brazilian version of PSS shows a satisfactory level of intern consistency ( $\alpha=0.83$, Dias et al., 2015). This measure was collected only in 2020 and coded as PSS2020. 


\section{Procedure}

The 2019 assessment was part of a broader study which aimed to characterize mental health and psychological suffering among Brazilian postgraduate students and took place between March and July - therefore, before the first documented global case of COVID-19, which occurred in December 2019. Participants were recruited from social media websites and filled an electronic form with average duration of 30 minutes. The form was made up of the aforementioned instruments, in addition to other measures that were not included in the present study. Following the spread of the pandemic in 2020, an e-mail with an invitation for the 2020 assessment was sent to all of the 2019 participants that had agreed to take part in follow-up studies ( $n=1502)$, and 619 (41.2\%) of them accepted to participate in the present study. The research protocol was then sent to the participants by e-mail in April 2020 - a month after the propagation of social distancing measures in Brazil, that started by the second fortnight of March 2020. The protocol required about 15 to 20 minutes to be answered. All respondents provided informed consent at each period of the study. The study protocol was approved by Ethics Committee (CAAE 07077019.3.0000.5149).

\section{Data Analysis}

Univariate descriptive analysis was conducted using the psych package, version 2.0.9 (Revelle, 2020), and multivariate normality analysis was carried out with the semTools package, version 0.5-3 (Jorgensen et al., 2018) in R software, version 4.0.2 (R Core Team, 2020). Invariance testing (configural, metric and scalar) for DASS-21, SWLS and FSII was conducted comparing the scores in 2019 and 2020 and applying the packages lavaan, version 0.6-7 (Rosseel, 2012), semTools, version 0.5-3 (Jorgensen et al., 2018), and semPlot, version 1.1.2 (Epskamp et al., 2019). The configural model is rejected in case Confirmatory Fit Index, $\mathrm{CFI}<.90$ or Root Mean Square Error of Approximation, RMSEA $\geq .10$ (Schumacker \& Lomax, 2016). Both the metric and the scalar invariance models are compared to the configural invariance model. They are rejected if they show together a difference of $\mathrm{CFI}>.002$ and $p<.01$ in the Chi-square statistical test of differences of the Satorra-Bentler method (2001). In case of rejection of the scalar invariance model, further analysis is made in search of the scalar invariance model in which the CFI difference, from the configural invariance model, is equal or inferior to .002 or p-value is equal or superior to .01 in the Chi-square of the Satorra-Bentler method (2001). In case the scalar model does not show relaxation over than $20 \%$ of the constrained parameters of the full scalar invariance model, the model is considered partially adequate and capable of allowing the comparison of the scores of the analyzed groups (Putnick \& Bornstein, 2016).

After invariance analyses, a path analysis was conducted over three models, including the following variables: FSII2020, FSIl2019, PSS2020, DASS2020, DASS2019, SWLS2020, SWLS2019, Neurot2019, Consc2019, and the Pandemic Impact variable (collected through the pandemic perception questionnaire). The path analysis approach was chosen over other alternatives, such as Structural Equations Modelling (SEM), on the grounds of two main reasons. First, the invariance factor analyses indicated a good relationship between the factorial loads of both the latent variables and their items, suggesting that total scores would not produce significant noise. In this sense, even though a path analysis would not correct for the scores' noise, it would also not produce biased results on our data. Second, the present sample size is not large enough to allow an adequate parameter estimation for SEM, in which the scales' items are included in the model, as well as a latent variables series. In summary, there is a sample size limitation which favored the use of path analysis over SEM. For the path analyses, the packages used are the same as in the invariance analyses of the questionnaires. Finally, a multigroup analysis of the model with the best fit was conducted. The three invariance models analyzed were: (i) invariance of causal relations among the variables; (ii) invariance of intercepts; (iii) invariance of intercepts and regressors. The compared groups were the male $(n=169)$ and 
female $(n=450)$ participants (gender 2020 variable) and the heterosexual $(n=482)$ and LGBTQ+ $(n=$ 129) orientation participants (sexual orientation 2020 variable; 8 "other"/"no response" participants were excluded from this group analysis). Here, the packages used are the same as in the invariance analyzes of the questionnaires.

\section{Results}

\section{Descriptive Analysis}

Participants' scores in SWLS items did not present multivariate normality. The hypothesis of multivariate normality distribution was rejected (Mardia kurtosis = 42.03; $\mathrm{z}=14.79 ; \mathrm{p}<.001$; Mardia skew $=2.34 ; \chi^{2}[35]=483.73 ; p<.001$ ). The hypothesis of multivariate normality distribution was also rejected for DASS-21 (Mardia kurtosis $=565.98 ; \mathrm{Z}=$ 46.97; $\mathrm{p}$ <.000009; Mardia skew = 24.02; $\chi^{2}$ [1771] = 4956.50; $p<.001$ ) and FSII (Mardia kurtosis = 113.70; $z=165.48 ; p<.001 ;$ Mardia skew = 36.94; $\chi^{2}[35]=$ 7622.97; $p<.001$ ). A table with mean values and standard deviations for each of the scales was not presented here for optimization of space but can be requested from the authors.

\section{Invariance Test of the Measures}

Only the results of the configural and scalar invariances will be presented here for optimization of space, but results for metric invariance can be requested from the authors. Considering the rejection of the null hypothesis that the scales presented multivariate normality, a robust maximum likelihood estimation was used to run the invariance analysis of the scales. For SWLS, a model of one latent variable to explain the 5 items of the scale was tested. Firstly, the configural invariance model for SWLS showed good fit $\left(\chi^{2}[10]=11.41 ; \mathrm{CFI}=1.00 ; \mathrm{RMSEA}=.015 ; \mathrm{RMSEA} \mathrm{Cl}\right.$ 90\% least value <.001; RMSEA Cl 90\% greatest value $=.048)$. The model for scalar invariance was rejected $\left(\chi^{2}[18]=48.65 ; \mathrm{CFI}=.991 ; \mathrm{RMSEA}=\right.$ .052 ; RMSEA Cl 90\% least value $=.035$ : RMSEA Cl $90 \%$ greatest value $=.070$ ). The model showed a chi-square greater than the configural model $\left(\Delta x^{2}[8]=36.33 ; p=1.52 e-05\right)$ and a CFI difference superior to $.002(\triangle \mathrm{CFI}=.009)$. The partial scalar invariance model with relaxation of intercepts on items 1 and 4 was not rejected $\left(\chi^{2}[16]=21.84 ; \mathrm{CFI}\right.$ $=.998 ;$ RMSEA = .024; RMSEA Cl 90\% least value = .000; RMSEA Cl 90\% greatest value $=.047$ ). It did not present chi-squares statistically superior to the configural model $\left(\Delta x^{2}[6]=10.07 ; p=.1218\right)$ and its $C F I$ difference was not superior to .002 ( $\triangle C F I$ $=.002$ ). This model indicates there has been an increment of .172 standard deviation to the SWLS scores between 2019 and 2020 (p-value = .007).

A one latent variable model was also applied to test for FSII invariance. The configural invariance model for FSII showed good fit to the data $\left(\chi^{2}[6]=\right.$ 11.50; CFI = .999; RMSEA = .039; RMSEA Cl 90\% least value <.001; RMSEA CI 90\% least value = .072). The metrical invariance model could not be rejected $\left(\chi^{2}[10]=35.27 ; \mathrm{CFI}=.995 ; \mathrm{RMSEA}=.064 ; \mathrm{RMSEA} \mathrm{Cl}\right.$ $90 \%$ least value $=.042 ;$ RMSEA Cl 90\% least value = .087). The scalar invariance model was not rejected as well $\left(\chi^{2}[14]=38.60 ; \mathrm{CFI}=\right.$.995; RMSEA = .053; RMSEA Cl 90\% least value = .034; RMSEA Cl 90\% greatest value $=.074$ ) . The model did not show a chi-square statistically superior to the configural model $\left(\Delta x^{2}[8]=12.30 ; p=.1385\right)$, although it did show a $C F I$ difference over .002 $(\triangle C F I=.004)$. This model indicates there has not been a statistically significant increment to FSII between 2019 and 2020 (.099 in favor of 2019, but with a p-value of .085).

For DASS-21, a bifactorial model with one general factor and three specific ones, all of them orthogonalized, was tested. The specific factor 1 carried items $3,5,10,13,16,17$, and 21; specific factor 2 carried items 4, 7, and 19; and specific factor 3 carried items 9, 11, 12, and 15. Items 17 and 21 were correlated. Configural invariance model for DASS showed acceptable fit $\left(\chi^{2}[348]=1237.69 ; \mathrm{CFI}=.944\right.$ RMSEA = .064; RMSEA Cl 90\% least value = .060; RMSEA Cl 90\% greatest value $=.068)$. The scalar invariance model was rejected $\left(\chi^{2}[396]=1322.53\right.$; $\mathrm{CFI}=.941$; RMSEA = .061; RMSEA Cl 90\% least value $=.058$; RMSEA Cl 90\% greatest value $=.065)$. It showed a chi-square greater than the configural model $\left(\Delta \chi^{2}[48]=81.17 ; p<.001\right)$ and a CFI difference superior to $.002(\triangle \mathrm{CFI}=.003)$. The partial scalar invariance model with relaxation of the intercepts at item 15 was not rejected $\left(\chi^{2}[395]=1313.56\right.$; CFI 
$=.942 ;$ RMSEA = .061; RMSEA Cl 90\% least value $=.058 ;$ RMSEA Cl 90\% greatest value $=.065$ ). This partial model showed a chi-square statistically superior to the configural $\left(\Delta x^{2}[47]=72.66 ; p<.001\right)$, but its $C F I$ difference was not superior to $002(\triangle C F I$ $=.002$ ). This model suggests that there has been a decrease of 187 standard deviation of DASS-21 scores between 2019 and 2020 ( $p$-value = .002).

\section{Path Analysis}

Model 1 showed inadequate fit to the data $\left(\chi^{2}[15]=521.34 ; \mathrm{CFI}=.630 ; \mathrm{RMSEA}=.242\right.$, RMSEA $\mathrm{Cl}$ 90\% least value $=.224$; RMSEA Cl 90\% greatest value $=.260$ ) and was rejected. Figure 1 presents the loads and correlations found in Model 1. Model 2 showed good fit to the data $\left(\chi^{2}[15]=26.22\right.$; CFI $=.992 ; \mathrm{RMSEA}=.035 ; \mathrm{RMSEA} \mathrm{Cl} 90 \%$ least value $=.009 ; \mathrm{RMSEA} \mathrm{Cl} \mathrm{90 \%} \mathrm{greatest} \mathrm{value} \mathrm{=} \mathrm{.056)}$ This second model was identical to the first one, but five new relations/associations were added
(FSII2O2O FSII2019; DASS2020 DASS2019; DASS2O2O FSIl202O; FSII2O2O SWLS2O2O; PSS2020 Pandemic Impact), and the relations in the model which were not statistically significant were excluded. Model 3, in Figure 2, showed good fit to the data $\left(\chi^{2}[13]=25.15 ; \mathrm{CFI}=.991 ; \mathrm{RMSEA}=\right.$ .039; RMSEA Cl 90\% least value = .014; RMSEA Cl $90 \%$ greatest value $=.061$, and did not exhibit any difference in adjustment in comparison to Model 2 $\left(\Delta \chi^{2}[2]=0.72 ; p=\right.$.6957). This third model is identical to Model 2, except that two relations were added (DASS2020 FSIl2019; FSII2020 DASS2019). Although its fit was similar to Model 2, the loads of these relationships were negligible (-.020, $\mathrm{p}$-value $=.664$ and $-.033, \mathrm{p}$-value $=.423$ ), adding no new information. In conclusion, Model 2 was considered the most adequate representation of the causal relations between the tested variables.

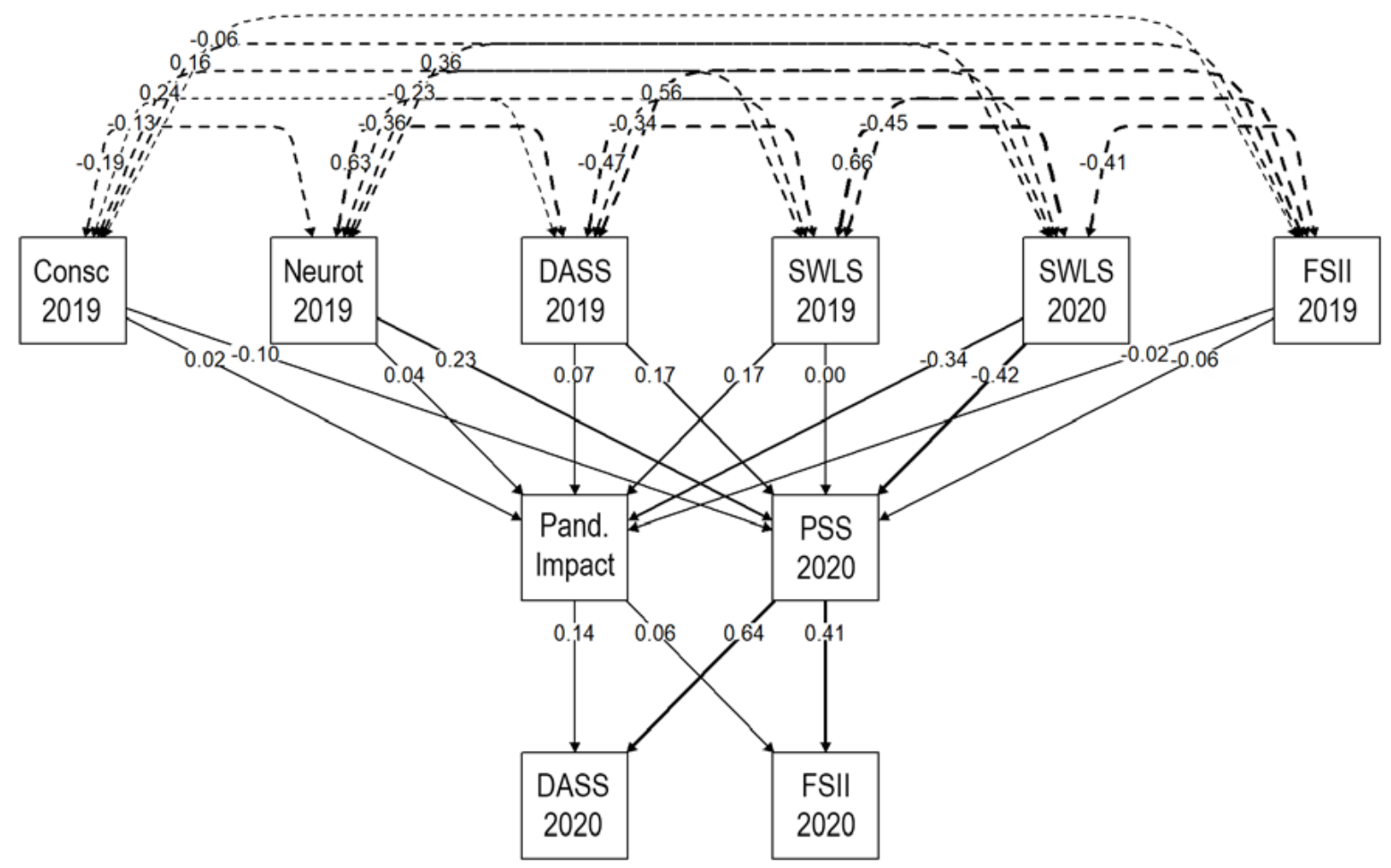

Figure 1 - Model 1 Path Analysis between predictor variables and moderators, and pandemic mental health outcomes Note. Coefficients presented are standardized linear regression coefficients (single-headed arrows) and correlations (double-headed arrows) found in Model 1. FSII2020: Frequency of Suicidal Ideation from 2020; FSII2019: Frequency of Suicidal Ideation from 2020; PSS2020: Perceived Stress Scale from 2020; DASS2020: DASS-21 from 2020; DASS2019: DASS-21 from 2019; SWLS2020: Satisfaction with Life Scale from 2020; SWLS2019: Satisfaction with Life Scale from 2019; Neurot2019: Neuroticism from 2019; Consc2019: Conscientiousness from 2019; Pand. Impact: Pandemic Impact from 2020. All the relationships shown in the model are statistically significant at $p-v a l u e<.05$. 


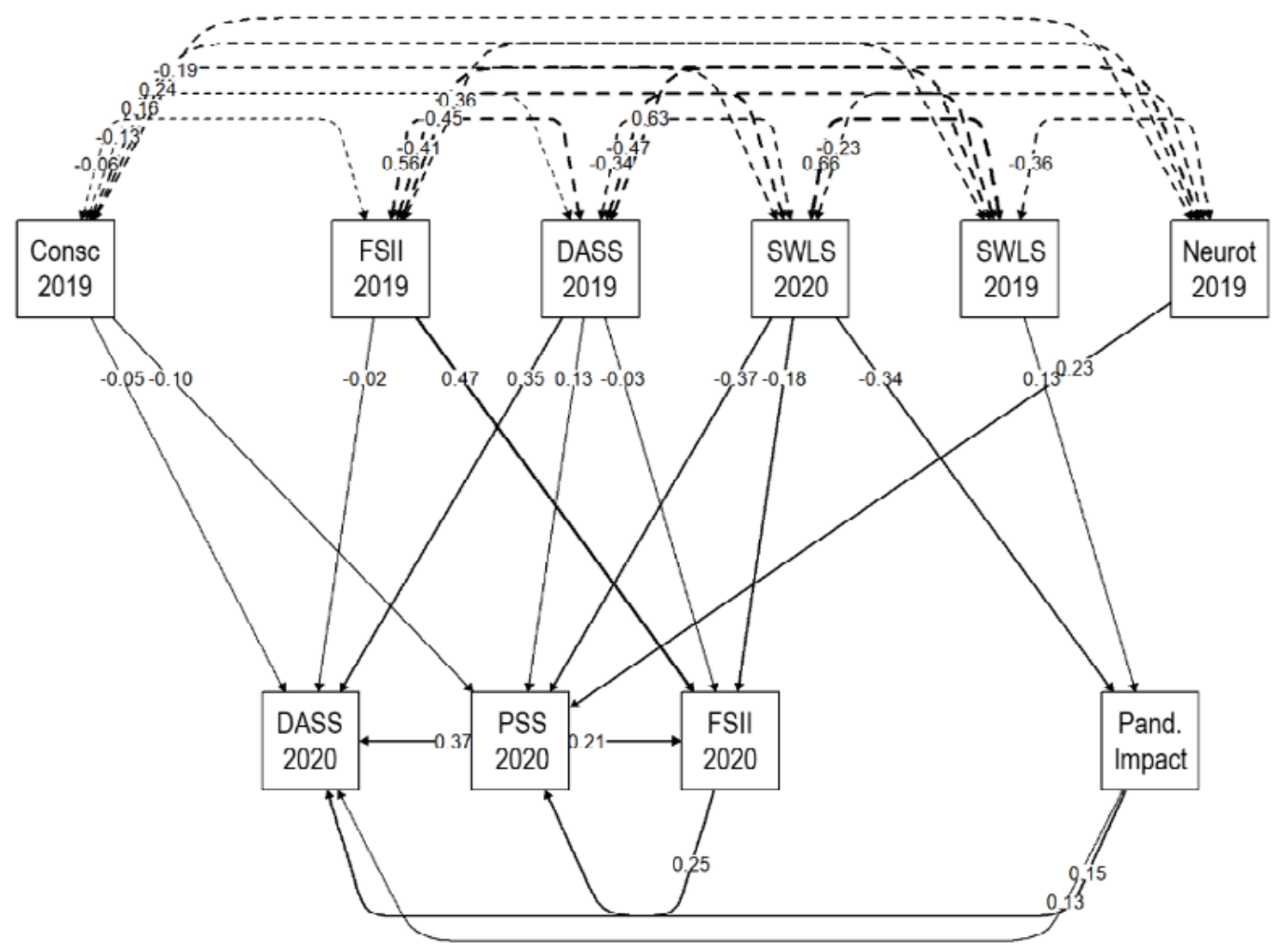

Figure 2 - Model 3 Path Analysis between predictor variables and moderators, and pandemic mental health outcomes

Note. Coefficients presented are standardized linear regression coefficients (single-headed arrows) and correlations (double-headed arrows) found in Model 3. FSII2020: Frequency of Suicidal Ideation from 2020; FSII2019: Frequency of Suicidal Ideation from 2020; PSS2020: Perceived Stress Scale from 2020; DASS2020: DASS-21 from 2020; DASS2019: DASS-21 from 2019; SWLS2020: Satisfaction with Life Scale from 2020; SWLS2019: Satisfaction with Life Scale from 2019; Neurot2019: Neuroticism from 2019; Consc2019: Conscientiousness from 2019; Pand. Impact: Pandemic Impact from 2020. All the relationships shown in the model are statistically significant at $p$-value $<.05$.

Figure 3 presents the loads and correlations found in Model 2 (all the relationships in the model are statistically significant at $p$-value $<.05$ ). The proportion of variance explained by the variables in the model for the participants' scores in DASS2O2O, FSII2020, and PSS2O20 were, respectively, 64\%, $45 \%$, and $41 \%$. DASS 2020 was directly explained by the scores of the participants in the previous year (DASS2019), conscientiousness in the previous year (Consc2019; although with low predictive value = $-0,05)$, as well as by the scores in PSS2020. Also, DASS2020 was correlated with 2020 FSII scores, but not explained by them. As for PSS2020 scores, they correlated with DASS scores of the same year, and its variance was explained by the scores in
DASS (DASS2019), neuroticism (Neurot2019) and conscientiousness (Consc2019) from the previous year, as well as by the SWLS scores (SWLS2020), and Pandemic Impact, both from 2020. FSII2O2O was correlated with DASS2020, and its variance was explained by scores FSII scores from the previous year (FSII2019), as well as by SWLS (SWLS2020) from the same period. The subjective perception of Pandemic Impact was explained in $8 \%$ of its variance, and 2020 ESV was its most important predictor, suggesting that increases in self-reported life satisfaction in 2020 were accompanied by reduction on participants' perception that their life was affected by the pandemic. 


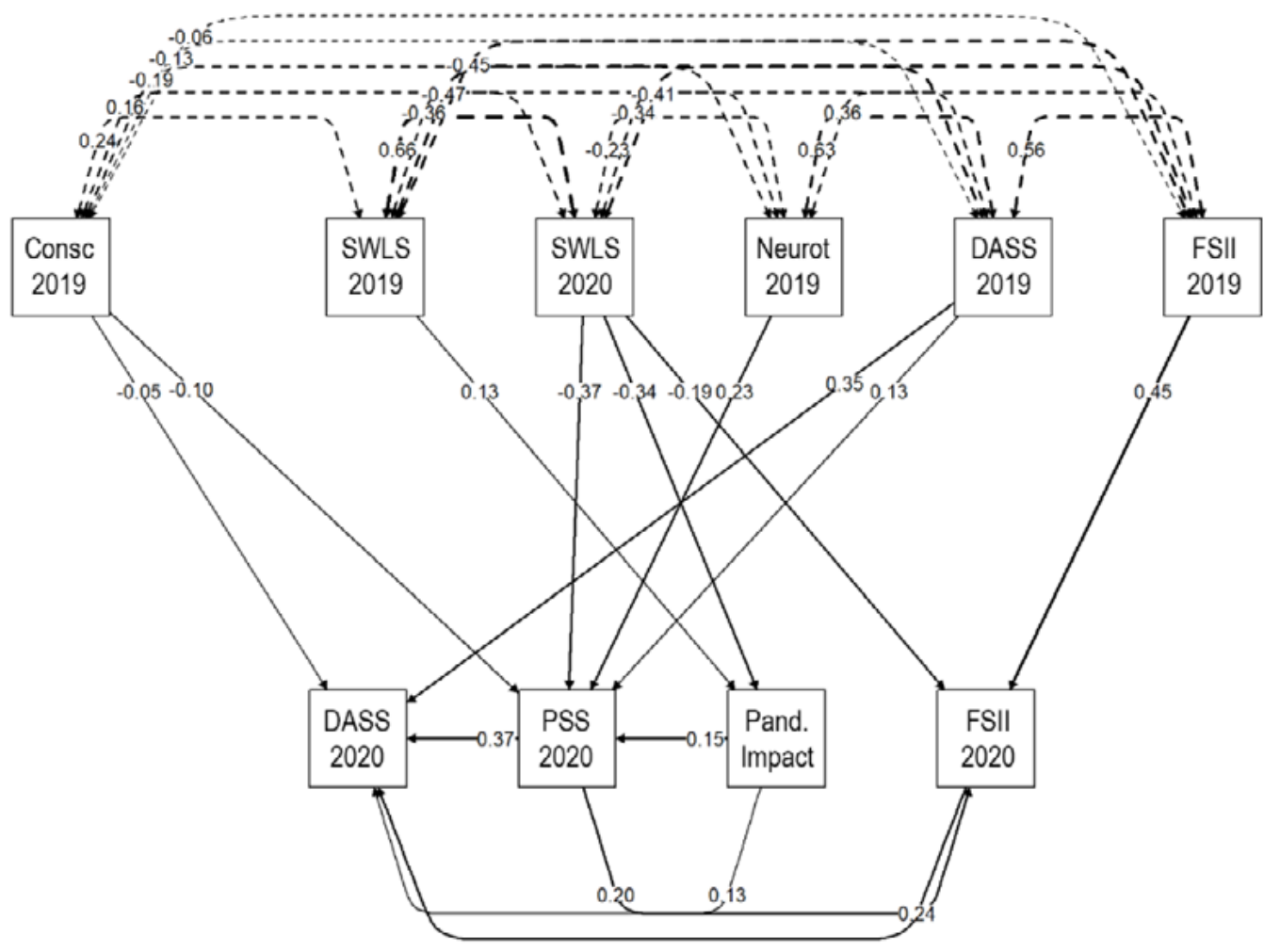

Figure 3 - Model 2 Final Path Analysis between predictor variables and moderators, and pandemic mental health outcomes

Note. Coefficients presented are standardized linear regression coefficients (single-headed arrows) and correlations (double-headed arrows) found in Model 2, the best fitting model. FSII202O: Frequency of Suicidal Ideation from 2020; FSII2019: Frequency of Suicidal Ideation from 2020; PSS2020: Perceived Stress Scale from 2020; DASS2020: DASS-21 from 2020; DASS2019: DASS-21 from 2019; SWLS2020: Satisfaction With Life Scale from 2020; SWLS2019: Satisfaction With Life Scale from 2019; Neurot2019: Neuroticism from 2019; Consc2019: Conscientiousness from 2019; Pand. Impact: Pandemic Impact from 2020. All the relationships shown in the model are statistically significant at $p$-value $<.05$.

Model 2 was tested for invariance between gender and sexual orientation categories. The model was constrained to present the same causal relations for men and women. This configural model demonstrated good fit $\left(\chi^{2}[30]\right.$ = 30.00; CFI = .994; RMSEA = .030; RMSEA Cl 90\% least value <.001; RMSEA Cl 90\% greatest value = .056). Next, Model 2 was constrained as to present the same regression parameters for both men and women $\left(\chi^{2}[45]=56.78 ; \mathrm{CFI}=.991 ; \mathrm{RMSEA}=\right.$ .029: RMSEA Cl 90\% least value <.001; RMSEA Cl $90 \%$ greatest value $=.050$ ). Although this model demonstrated a CFI difference over .002, it did not show statistically significant differences to the configural model $\left(\Delta x^{2}[14]=14.46 ; p=.4161\right)$. Afterwards, Model 2 was constrained to show the same regression parameters and intercepts for men and women $\left(\chi^{2}[49]=72.48 ; \mathrm{CFI}=.983\right.$; RMSEA $=.039 ; \mathrm{RMSEA} \mathrm{Cl} 90 \%$ least value $=.017$; RMSEA $\mathrm{Cl}$ 90\% greatest value $=.058$ ). Again, although it showed CFI differences superior to .0002, there was no statistically significant difference between the configural model and this one $\left(\Delta x^{2}[19]=27.07\right.$; $\mathrm{p}=$.1031). In conclusion, predictive relations from Model 2, as well as their regressions results and intercepts, are the same for men and women.

Model 2 was also constrained to display the same causal relations for people with heterosexual and LGBTQ+ orientation, and demonstrated good fit to the data $\left(\chi^{2}[30]=43.10 ; \mathrm{CFI}=.990 ; \mathrm{RMSEA}=\right.$ .038; RMSEA Cl 90\% least value < .001; RMSEA $\mathrm{Cl} 90 \%$ greatest value $=.061$ ). The model was 
then constrained to show the same regression parameters for both groups $\left(\chi^{2}[45]=62.95 ; \mathrm{CFI}=\right.$ .985: RMSEA = .036; RMSEA Cl 90\% least value = .008; RMSEA Cl 90\% greatest value $=.056$ ). The model did present a CFI difference over .002, but no statistically significant difference to the configural model $\left(\Delta \chi^{2}[15]=17.13 ; p=.3108\right)$. Finally, Model 2 was constrained to show the same regression parameters and intercepts $\left(\chi^{2}[49]=67.06 ; \mathrm{CFI}=.986\right.$; RMSEA = .035: RMSEA Cl 90\% least value = .006; RMSEA Cl 90\% greatest value = .054), and, again, even though it demonstrated a CFI difference superior to .002, it did not show any statistically significant difference against the configural model $\left(\Delta x^{2}[19]=21.41 ; p=.3148\right)$. In summary, predictive relations from Model 2, as well as their regression results and intercepts, are the same for people from both sexual orientation groups.

\section{Discussion}

The main objective of the present study was to test a longitudinal prediction model for general psychological suffering and suicidal ideation frequency amongst post-graduate students, by means of comparing measures collected at the beginning of the adoption of social distancing measures in Brazil during the COVID-19 pandemic (April 2020), with the same measures collected around a year before the break of the pandemic (March-July 2019). Variables such as personality traits, life satisfaction, perceived stress, and the subjective perception of how much one has been affected by the pandemic (Pandemic Impact) were included in the model as 2020 mental health outcome predictors, as well as psychological symptoms and suicidal ideation from the previous year (2019). For this purpose, invariance analysis of the scales from each period have been conducted to assure that 2019 and 2020 total scores were comparable.

First, the frequency of suicidal ideation in 2020 was positively correlated with general psychological suffering by 2020 . This result has also been found in other studies (Ammerman et al., 2020; Franklin et al., 2017; Wetherall et al., 2020) and points out to the fact that thoughts of hopelessness and sadness, and intense experiences of suffering and grief are probably comorbid with anxiety and depression, even though there is no necessary causal relation between them. Interestingly, in the longitudinal model that demonstrated the best fit indices, frequency of suicidal ideation in 2020 (during the pandemic) had $45 \%$ of its variance predicted uniquely by the frequency of suicidal ideation in 2019 (before the pandemic), and life satisfaction in 2020 (negatively). Frequency of suicidal ideation in 2019 was the best predictor for the same variable in 2020, which might suggest that, although the assessment of suicidal ideation is based on shortterm temporal criteria (e.g. last week, last month), there is some aspect of psychological functioning that is more stable, and that maintains these kind of self-injurious thoughts for longer periods of time, and does not seem to correspond neither to a personality trait (such as neuroticism), nor to the existence of previous mental distress (as measured by 2019 DASS-21). In this sense, it could be argued that this stability is not restricted to the COVID-19 context, but more evidence to support this claim should be gathered in future studies.

Notably, subjective perception of pandemic impact over one's life was not capable of predicting frequency of suicidal ideation in 2020 , which goes against previous findings from crosssectional studies carried out in other countries (Ammerman et al., 2020). The present results might be explained by the data collection period that took place a month after the start of social distancing measures in Brazil, which may be a relatively short period of time for the development of suicidal ideations. On the other hand, individual perception of well-being in 2020 was an important predictor of the frequency of suicidal ideation in the same year. Feeling good about oneself and one's own life seems to be a protective factor against the detrimental effects of stress and excessive adverse and traumatic life events, and is, in fact, part of the modern concept of mental health (Galderisi et al., 2015). This observation seems to be corroborated not only by other studies in the field of mental health (Fergusson et al., 2015; Siegmann et al., 2017), but also by other findings of the present study. 
Life satisfaction during the pandemic moderately and negatively predicts both perceived stress in the same period (2020) and the perception of how much the changes that come with the pandemic control measures affect daily life. Therefore, the most satisfied with life post-graduate students showed lower levels of perceived stress and felt like their lives had been less affected by the changes they had been through during the first month of the COVID-19 pandemic. Similar findings were also found in cross-sectional studies (Ammerman et al., 2020; Casali, 2020; Pradhan et al., 2020). Collectively, these results strengthen the account of perceived well-being as a protective factor that reduces negative effects of stress. It should be noted that a sense of satisfaction with life does not imply that individuals will not experience negative life events or setbacks. Conversely, it is associated with the acknowledgement that, even though bad things happen to everyone, they can still see that there are reasons for living, and that they have further resources to help them overcome challenges. In this sense, life satisfaction might be associated with values, with personality characteristics linked to optimism and positive affect, and also with self-efficacy, which may collectively bestow life satisfaction with its aforementioned protective effects (Dyrenforth et al., 2010; Marcionetti \& Rossier, 2016).

As for general psychological suffering experienced during the pandemic, the bestfitting model explained $64 \%$ of variance for DASS-21, to which total DASS-21 scores in 2019 (pre-pandemic), and perceived stress during the pandemic were the best direct predictors. That is, adults that had already shown higher levels of anxiety and depression symptoms by 2019 seemed to be experiencing higher levels of these same symptoms throughout the beginning of the pandemic. Nevertheless, the degree to which individuals believe their lives are unpredictable, uncontrollable, and overwhelming (perceived stress) significantly contribute to the intensification of symptoms of anxiety and depression during the pandemic. It is worth highlighting that, to complete the perceived stress scale, the respondent had to consider the month previous to the assessment, which, in the case of the present study, corresponded to the start of social distancing measures in Brazil (March 2020). These findings converge with previous studies - conducted before and during the pandemic - which point up the surge of mental distress as a response (adaptive if not intense or recurrent) to abrupt environmental changes, that require the organism to activate defense and protection systems (Salari et al., 2020). Mari e Oquendo (2020) emphasize that anxiety, depression, substance abuse, and post-traumatic disorders are commonly observed after major catastrophes. The authors underline how the first wave of COVID-19 effects over mental health are acute stress responses to: the arrival of an unexpected and unknown disease; the speed with which it caused changes of habits, routine, and relationships; and the uncertainty over how much time these changes will last (Mari \& Oquendo, 2020).

However, beyond direct effects, the present longitudinal model indicate that other variables seem to contribute indirectly to the degree of psychological distress experienced during the COVID-19 pandemic. Both neuroticism (positively) and conscientiousness (negatively) in 2019 are associated with levels of perceived stress observed in 2020, and these, in turn, are related to general psychological suffering in 2020. These findings are in line with cross-sectional studies which investigated the role played by personality traits in the adherence to COVID-19 containment measures, and in the heightening of fear, perceived risk, and perceived stress levels (Carvalho et al., 2020; Lippold et al., 2020; Liu et al., 2021; Mikcevic et al., 2020). Hence, it could be suggested that people with higher levels of neuroticism (negative affect) are more susceptible to negative bias and lack of emotional regulation strategies when facing unexpected events, which, associated with reduced self-efficacy and ability to take on self-protection measures (lower level of conscientiousness), leaves them more prone to experiencing higher levels of stress during the pandemic, which, in turn, may add to the psychological suffering. It is also worth highlighting that life satisfaction scores (cross- 
sectional and longitudinal) seem to indirectly impact, as seen in the modeling done, the degree of psychological suffering among participants, through the (negative) influence they exert on the levels of perceived stress and subjective pandemic impact. As mentioned before, life satisfaction is, currently, one of the most important components of mental health models (Galderisi et al., 2015; Marcionetti \& Rossier, 2016).

Finally, the best fitting model was tested for invariance regarding sex (feminine and masculine) and sexual orientation (heterosexual and LGBTQ+), since literature indicates that women and LGBTQ+ groups were the most affected by the pandemic, showing higher levels of psychological suffering (Di Crosta et al., 2020; Suen et al., 2020). The findings of the present study demonstrate invariance of the longitudinal model for both gender and sexual orientation. This is highly informative for two main reasons. First, because it follows the assertion that these groups' averages can truly be compared. However, above all, it demonstrates that even though men and women, and heterosexuals and LGBTQ+, have distinct levels of psychological suffering, their predictive factors seem to be shared - at least when considering the pandemic context analyzed in the present study. Nonetheless, it should be noted that other factors that were not included in the present analyses (such as excess of responsibilities and work overload due to the pandemic; triple journey; need for confinement with family or people from unhealthy, unaccepting and uncaring relationships) could add to the explained variance of the model, and offer an even more comprehensive understanding of the documented differences between men, women, heterosexuals and LGBTQ+ (Auerbach et al., 2018; Kneale \& Becares, 2020; Suen et al., 2020).

There are a few limitations to the present study. Data collected in 2020 correspond to the first four weeks of social distancing in Brazil. In this sense, even though there is evidence that acute effects over mental health take place during health emergencies and crisis, a greater negative effect due to the pandemic, and especially due to social distancing measures, might take a longer period to become apparent. Moreover, because participants were post-graduate students, specific variables related to difficulties experienced in graduate school could interfere with general psychological suffering levels yet were not controlled in the present study. Finally, we used only self-report measures, and our sample size did not allow the use of a SEM strategy that could account for latent variables, and thus our analyses are based on scales' total scores. Despite these limitations, this is one of the only studies that have attempted to compile, into one predictive longitudinal model, pre-pandemic individual variables and individual COVID-19 related experiences, to better understand the psychological suffering endured in the course of the pandemic.

\section{Conclusion}

The COVID-19 pandemic gave rise to countless public health challenges and caused major individual, social, and economic impacts over most of the global population, requiring collective, coordinated, and cooperative actions. Mental health is certainly an issue that calls for attention in this scenario, considering the extensive changes in life (work, leisure, domestic and social life) experienced by the population in the effort to contain the virus.

The longitudinal model developed in the present study aims to contribute to the understanding of mental health outcomes (psychological suffering and suicidal ideation) during the pandemic period, especially through psychological variables assessed in the year before the pandemic. The tested model highlights the importance of integrating both more stable individual factors and less stable variables towards an explanation for these outcomes. This examination of stable and transient explanatory factors of a phenomenon should enable the development of preventive mental health policies that are better aligned to individual differences, while still guiding authorities and mental health workers towards health prevention and promotion strategies and efforts focused on factors that are easier to change. 


\section{References}

Ammerman, B. A., Burke, T. A., Jacobucci, R., \& McClure, K. (2020). Preliminary investigation of the association between COVID-19 and suicidal thoughts and behaviors in the U.S. PsyArXiv. https://doi.org/10.31234/osfio/68dip

Auerbach, R. P., Mortier, P., Bruffaerts, R., Alonso, J., Benjet, C., Cuijpers, P., Demyttenaere, K., Ebert, D. D., Green, J. G., Hasking, P., Murray, E., Nock, M. K., Pinder-Amaker, S., Sampson, N. A., Stein, D. J., Vilagut, G., Zaslavsky, A. M., Kessler, R. C., \& WHO WMH-ICS Collaborators (2018). WHO World Mental Health Surveys International College Student Project: Prevalence and distribution of mental disorders. Journal of abnormal psychology, 127(7), 623-638. https://doi.org/10.1037/abno000362

Brooks, S. K., Webster, R. K., Smith, L. E., Woodland, L., Wessely, S., Greenberg, N., \& Rubin, G. J. (2020). The psychological impact of quarantine and how to reduce it: rapid review of the evidence. The Lancet, 395(10227), 912-920. https://doi.org/10.1016/S01406736(20)30460-8

Caci B., Miceli S., Scrima F., \& Cardaci M. (2020). Neuroticism and Fear of COVID-19: the interplay between boredom, fantasy engagement, and perceived control over time. Front. Psychol, 11, Article 574393. https://doi. org/10.3389/fpsyg.2020.574393

Carvalho L. F., Pianowski G., \& Gonçalvez A. P. (2020). Personality differences and COVID-19: are extroversion and conscientiousness personality traits associated with engagement with containment measures? Trends Psychiatry Psychother, 42(2), 179-184. http://dx.doi. org/10.1590/2237-6089-2020-0029

Casali, N., Feraco, T., Ghisi, M., \& Meneghetti, C. (2020). "Andrà tutto bene": Associations Between Character Strengths, Psychological Distress and Self-efficacy During Covid-19 Lockdown. J Happiness Stud, 22, 22552274. https://doi.org/10.1007/s10902-020-00321-W

Chang, E. C., \& Chang, O. D. (2016). Development of the Frequency of Suicidal Ideation Inventory: Evidence for the validity and reliability of a brief measure of suicidal ideation frequency in a college student population. Cognitive Therapy and Research, 40(4), 549-556. https:// doi.org/10.1007/s10608-016-9758-0

Cohen, S., Kamarck, T., \& Mermelstein, R. (1983). A global measure of perceived stress. Journal of Health and Social Behavior, 24(4), 385-396. https://doi. org/10.2307/2136404

Di Crosta, A., Palumbo, R., Marchetti, D., Ceccato, I., La Malva, P., Maiella, R., Cipi, M., Roma, P., Mammarella, N., Verrocchio, M. C. \&, Di Domenico, A. (2020). Individual Differences, Economic Stability, and Fear of Contagion as Risk Factors for PTSD Symptoms in the COVID-19 Emergency. Front. Psychol, 11, Article 567367. https:// doi.org/10.3389/fpsyg.2020.567367

Dias, J., Silva, W., Maroco, J., \& Campos, J. (2015). Perceived Stress Scale Applied to College Students: Validation Study. Psychol. Community Health, 4(1), 1-13. https://doi. org/10.5964/pch.v4i1.90
Diener, E., Emmons, R. A., Larsen, R. J., \& Griffin, S. (1985). The Satisfaction With Life Scale. Journal of Personality Assessment, 49, 71-75.

Dyrenforth, P. S., Kashy, D. A., Donnellan, M. B., \& Lucas, R. E. (2010). Predicting relationship and life satisfaction from personality in nationally representative samples from three countries: The relative importance of actor, partner, and similarity effects. Journal of personality and social psychology, 99(4), 690-702. https://doi. org/10.1037/a0020385

Epskamp, S., Stuber, S., Nak, J., Veenman, M., \& Jorgensen, T. D. (2019). Path diagrams and visual analysis of various SEM packages' output. R Package, version 1.1.2. https://github.com/SachaEpskamp/semPlot

Fergusson, D. M., McLeod, G. F. H., Horwood, L. J., Swain, N. R., Chapple, S., \& Poulton, R. (2015). Life satisfaction and mental health problems (18 to 35 years). Psychological medicine, 45(11), 2427-2436. https://doi. org/10.1017/So033291715000422

Franklin, J. C., Ribeiro, J. D., Fox, K. R., Bentley, K. H., Kleiman, E. M., Huang, X., Musacchio, K. M., Jaroszewski, A. C., Chang, B. P., \& Nock, M. K. (2017). Risk factors for suicidal thoughts and behaviors: A meta-analysis of 50 years of research. Psychological Bulletin, 143(2), 187-232. https://doi.org/10.1037/buloo00084

Galderisi, S., Heinz, A., Kastrup, M., Beezhold, J., \& Sartorius, N. (2015). Toward a new definition of mental health. World Psychiatry, 14(2), 231-233. https://doi. org/10.1002/wps.20231

Gouveia, V. V., Milfont, T. L., da Fonseca, P. N., \& Coelho, J. A. P. d. M. (2009). Life satisfaction in Brazil: Testing the psychometric properties of the Satisfaction With Life Scale (SWLS) in five Brazilian samples. Social Indicators Research, 9o(2), 267-277. https://doi.org/10.1007/ \$11205-008-9257-0

John, O. P., Donahue, E. M., \& Kentle, R. L. (1991). Big five inventory (BFI) [Database record]. APA PsycTests. https://doi.org/10.1037/t07550-000

Juric, L. C., Andrés, M. L., Del valle, M. V., López Morales, H., Poó, F., Galli, J., Yerro, M., \& Urquijo, S. (2020). A longitudinal study on the emotional impact cause by the COVID-19 pandemic quarantine on general population. Front. Psychol, 11, Article 2431, 1-17. https:// doi.org/10.3389/fpsyg.2020.565688

Kneale, D., \& Becares, L. (2020). The mental health and experiences of discrimination of $L G B T Q+p e-$ ople during the COVID-19 pandemic: initial findings from the Queerantine Study. medRxiv. https://doi. org/10.1101/2020.08.03.20167403

Lippold, J. V., Laske, J. I., Hogeterp, S. A., Duke, É., Grünhage, T., \& Reuter, M. (2020). The Role of Personality, Political Attitudes and Socio-Demographic Characteristics in Explaining Individual Differences in Fear of Coronavirus: A Comparison Over Time and Across Countries. Front. Psycho, 11, Article 552305. https://doi. org/10.3389/fpsyg.2020.552305 
Liu, S., Lithopoulos, A., Zhang, C.-Q., Garcia-Barrera, M. A., \& Rhodes, R. E. (2021). Personality and perceived stress during COVID-19 pandemic: Testing the mediating role of perceived threat and efficacy. Personality and Individual Differences, 168, Article 110351. https:// doi.org/10.1016/j.paid.2020.110351

Lovibond, S. H., \& Lovibond, P. F. (1996). Manual for the depression anxiety stress scales. Psychology Foundation of Australia.

Marcionetti, J., \& Rossier, J. (2016). Global life satisfaction in adolescence: The role of personality traits, self-esteem, and self-efficacy. Journal of Individual Differences, 37(3), 135-144. https://doi.org/10.1027/1614$0001 / a 000198$

Mari, J. D. J., \& Oquendo, M. A. (2020). Mental health consequences of COVID-19: The next global pandemic. Trends in Psychiatry and Psychotherapy, 42(3). https:// doi.org/10.1590/2237-6089-2020-0081

McCrae, R. R., \& Sutin, A. R. (2018). A Five-Factor Theory Perspective on Causal Analysis. European journal of personality, 32(3), 151-166. https://doi.org/10.1002/per.2134

Ministério da Saúde. (2020a). Portaria MS/GM n. 188, de 3 de fevereiro de 2020. Declara Emergência em Saúde Pública de importância Nacional (ESPIN) em decorrência da Infecção Humana pelo novo Coronavirus (2019-nCoV). Diário Oficial da União (Seção 1:1). https:// www.in.gov.br/web/dou/-/portaria-n-188-de-3-de-fevereiro-de-2020-241408388

Ministério da Saúde. (2020b). Secretaria de Vigilância em Saúde. Boletim Epidemiológico Especial. COE-COVID19.

Modersitzki, N., Phan, L. V., Kuper, N., \& Rauthmann, J. F. (2020). Who Is Impacted? Personality Predicts Individual Differences in Psychological Consequences of the COVID-19 Pandemic in Germany. Social Psychological and Personality Science, 12(6), 1110-1130. https://doi. org/10.1177/1948550620952576

Morales-Vives, F., Dueñas, J-M., Vigil-Colet, A., \& Camarero-Figuerola, M. (2020). Psychological Variables Related to Adaptation to the COVID-19 Lockdown in Spain. Front. Psychol., 11, Article 565634. https://doi. org/10.3389/fpsyg.2020.565634

Nikčević, A. V., Marino, C., Kolubinski, D. C., Leach, D., \& Spada, M. M. (2020). Modelling the contribution of the Big Five personality traits, health anxiety, and COVID-19 psychological distress to generalised anxiety and depressive symptoms during the COVID-19 pandemic. Journal of affective disorders, 279, 578-584. Advance online publication. https://doi.org/10.1016/j. jad.2020.10.053

Odriozola-González, P., Planchuelo-Gómez, Á., Irurtia, M. J., \& de Luis-Garcia, R. (2020). Psychological effects of the COVID-19 outbreak and lockdown among students and workers of a Spanish university. Psychiatry Research, 290, Article 113108. https://doi.org/10.1016/.jpsychres.2020.113108

Planchuelo-Gómez, Á., Odriozola-González, P., Irurtia, M. J., \& de Luis-García, R. (2020). Longitudinal evaluation of the psychological impact of the COVID-19 crisis in Spain. Journal of Affective Disorders, 277, 842-849. https://doi.org/10.1016/j.jad.2020.09.018
Pradhan, M., Chettri, A. \& Maheshwari, S. (2020). Fear of death in the shadow of COVID-19: The mediating role of perceived stress in the relationship between neuroticism and death anxiety. Death Studies, 1-5. https:// doi.org/10.1080/07481187.2020.1833384

Prati, G., \& Mancini, A. (2021). The psychological impact of COVID-19 pandemic lockdowns: A review and meta-analysis of longitudinal studies and natural experiments. Psychological Medicine, 51(2), 201-211. https:// doi.org/10.1017/S0033291721000015

Putnick, D. L., \& Bornstein, M. H. (2016). Measurement invariance conventions and reporting: The state of the art and future directions for psychological research. Developmental Review, 41, 71-90. https://doi.org/10.1016/j. dr.2016.06.004

R Core Team. (2018). R,version 4.0. [Computer software]. Vienna, Austria: R Foundation for Statistical Computing. http://WwW.r-project.org/

Revelle W. (2020). psych: procedures for psychological, psychometric, and personality research. R package, version 1.9.12.31. https://CRAN.R-project.org/package=psych

Rosseel, Y. (2012). lavaan: An R Package for Structural Equation Modeling. R package, version 0.6-5. http:// www.jstatsoft.org/v48/i02/

Salari, N., Hosseinian-Far, A., Jalali, R., Vaisi-Raygani, A., Rasoulpoor, S., Mohammadi, M., Rasoulpoor, S., \& Khaledi-Paveh, B. (2020). Prevalence of stress, anxiety, depression among the general population during the COVID-19 pandemic: a systematic review and meta-analysis. Globalization and health, 16(1), Article 57. https:// doi.org/10.1186/S12992-020-00589-W

Satorra, A., \& Bentler, P. M. (2001). A scaled difference chi-square test statistic for moment structure analysis. Psychometrika, 66, 507-514. https://doi.org/10.1007/ BF02296192

Schumacker, R., \& Lomax, R. (2016). A beginner's guide to structural equation modeling. Routledge.

Suen, Y., Chan, R. C. H., \& Wong, E. M. Y. (2020). Effects of general and sexual minority-specific COVID-19-related stressors on the mental health of lesbian, gay and bisexual people in Hong Kong. Psychiatry Research, 292, Article 113365. https://doi.org/10.1016/j. psychres.2020.113365

Teodoro, M., de Souza, R., Martins, C. C., Sediyama, C., Alvares-Teodoro, J., Chang, O. D., \& Chang, E. C. (2020). Validity of the Frequency of Suicidal Ideation Inventory in Brazilian adults. Death studies, 1-5. Advance online publication. https://doi.org/10.1080/07481187.2020.1824201

Siegmann, P., Teismann, T., Fritsch, N., Forkmann, T., Glaesmer, H., Zhang, X. C., ... Margraf, J. (2018). Resilience to suicide ideation: A cross-cultural test of the buffering hypothesis. Clinical psychology \& psychotherapy, 25(1), 1-9. https://doi.org/10.1002/cpp.2118

Vignola, R. C., \& Tucci, A. M. (2014). Adaptation and validation of the depression, anxiety and stress scale (DASS) to Brazilian Portuguese. Journal of affective disorders, 155, 104-109. https://doi.org/10.1016/j.jad.2013.10.031 
Wang, C., Pan, R., Wan, X., Tan, Y., Xu, L., Ho, C. S., \& Ho, R. C. (2020a). Immediate psychological responses and associated factors during the initial stage of the 2019 coronavirus disease (COVID-19) epidemic among the general population in China. Int. J. Environ. Res. Public Health, 17(5), Article 1729. https://doi.org/10.3390/ijerph1705172.

Wang, C., Pan, R., Wan, X., Tan, Y., Xu, L., McIntyre, R. S., Choo, F. N., Tran, B., Ho, R., Sharma, V. K., \& Ho, C. (2020b). A longitudinal study on the mental health of general population during the COVID-19 epidemic in China. Brain, behavior, and immunity, 87, 40-48. https:// doi.org/10.1016/j.bbi.2020.04.028

Wetherall, K., Cleare, S., McClelland, H., Zortea, T., Robb, K., \& O'Connor, R. (2020). Scottish COVID-19 (SCOVID) Mental Health Tracker Study: Wave 1 Report. ISBN: 9781800041622

Zhang, S. X., Wang, Y., Rauch, A., \& Wei, F. (2020). Unprecedented disruption of lives and work: Health, distress and life satisfaction of working adults in China one month into the COVID-19 outbreak. Psychiatry Research, 288, Article 112958. https://doi.org/10.1016/j. psychres.2020.112958

Zortea, T. C., Brenna, C., Joyce, M., McClelland, H., Tippett, M., Tran, M. M., Arensman, E., Corcoran, P., Hatcher, S., Heise, M. J., Links, P., O'Connor, R. C., Edgar, N. E., Cha, Y., Guaiana, G., Williamson, E., Sinyor, M., \& Platt, S. (2020). The Impact of Infectious Disease-Related Public Health Emergencies on Suicide, Suicidal Behavior, and Suicidal Thoughts. Crisis, o(0), 1-14. Advance online publication. https://doi.org/10.1027/0227-5910/a000753

\section{Marcela Mansur-Alves}

PhD in Neurosciences, Federal University of Minas Gerais (UFMG), Belo Horizonte, MG, Brazil. Professor in the Department of Psychology, Faculty of Philosophy and Human Sciences, Federal University of Minas Gerais (UFMG), Belo Horizonte, MG, Brazil.

\section{Cristiano Mauro Assis Gomes}

PhD in Education, Federal University of Minas Gerais (UFMG), Belo Horizonte, MG, Brazil. Professor in the Department of Psychology, Faculty of Philosophy and Human Sciences, Federal University of Minas Gerais (UFMG), Belo Horizonte, MG, Brazil.

\section{Camila Batista Peixoto}

Undergraduate student of Psychology, Faculty of Philosophy and Human Sciences, Federal University of Minas Gerais (UFMG), Belo Horizonte, MG, Brazil.

\section{Matheus Bortolosso Bocardi}

MSc in Cognition and Behavior, Federal University of Minas Gerais (UFMG), Belo Horizonte, MG, Brazil.

\section{Marina Luiza Nunes Diniz}

MSc in Cognition and Behavior, Federal University of Minas Gerais (UFMG), Belo Horizonte, MG, Brazil.

\section{Sabrina Kelly Pessoa de Freitas}

MSc student in Cognition and Behavior, Federal University of Minas Gerais (UFMG), Belo Horizonte, MG, Brazil.

\section{Elder Gomes Pereira}

MSc student in Cognition and Behavior, Federal University of Minas Gerais (UFMG), Belo Horizonte, MG, Brazil.

\section{Juliana Alvares-Teodoro}

PhD in Public Health, Federal University of Minas Gerais (UFMG), Belo Horizonte, MG, Brazil. Professor in the Department of Social Pharmacology, School of Pharmacy, Federal University of Minas Gerais (UFMG), Belo Horizonte, MG, Brazil.

\section{Pricila Cristina Correa Ribeiro}

$\mathrm{PhD}$ in Collective Health, Rio de Janeiro State University (UERJ), Rio de Janeiro, RJ, Brazil. Professor in the Department of Psychology, Faculty of Philosophy and Human Sciences, Federal University of Minas Gerais (UFMG), Belo Horizonte, MG, Brazil.

\section{Maycoln Leôni Martins Teodoro}

PhD in Developmental and Clinical Psychology, Albert Ludwigs Universität Freiburg, ALUF, Germany. Professor in the Department of Psychology, Faculty of Philosophy and Human Sciences, Federal University of Minas Gerais (UFMG), Belo Horizonte, MG, Brazil.

\section{Mailing address}

Marcela Mansur-Alves

Universidade Federal de Minas Gerais

Laboratório de Avaliação e Intervenção na Saúde

Av. Antônio Carlos, 6627, prédio da Faculdade de Filosofia e Ciências Humanas (FAFICH), sala 4006

Pampulha, 31270-901

Belo Horizonte, MG, Brasil

Os textos deste artigo foram submetidos para validação do(s) autor(es) antes da publicação. 